\title{
Retinoblastoma in Great Britain 1969-80: incidence, treatment, and survival
}

\author{
B M SANDERS,' G J DRAPER,' AND J E KINGSTON² \\ From the 'Childhood Cancer Research Group, Department of Paediatrics, University of Oxford, and the \\ ${ }^{2}$ Department of Paediatric Oncology, St Bartholomew's Hospital, London
}

SUMmaRy Patients with retinoblastoma diagnosed from 1969 to 1980 have been followed up for periods of up to 17 years. Data from a previous study of patients diagnosed from 1962 to 1968 have been included for analysis of incidence and second primary tumours, and for study of trends in treatment. The registration rate in Britain (which may be about $10 \%$ less than the true incidence) is about one in 23000 live births, approximately $40 \%$ of cases being known to be genetic. There is no apparent trend in incidence during the period covered by these two studies. The three-year survival rate is $88 \%$. Patients with bilateral tumours have a better survival rate than those with unilateral tumours for the first few years, but their long-term survival rate is worse because of later deaths from ectopic intracranial retinoblastoma or second primary neoplasms. Older children tend to have a worse prognosis, which is related to the fact that their tumours are diagnosed at a more advanced stage. There is a significantly higher survival rate for boys than for girls; this is partly accounted for by difference in age and stage at diagnosis between the sexes. Children referred to units specialising in the treatment of retinoblastoma have a higher three-year survival rate than those treated at other hospitals. Comparing methods of treatment between the periods 1962-8 and 1969-80, we find there has been a trend towards more conservative treatment. The use of chemotherapy is now usually reserved for recurrences and metastases and for palliative treatment in terminal retinoblastoma.

Retinoblastoma comprises about $3 \%$ of all the malignant tumours of childhood. The tumour may occur in only one or in both eyes and may be either unifocal or multifocal in origin. It occurs in both sporadic and inherited forms: the latter, which accounts for about $40 \%$ of all the cases, includes all bilateral tumours and a small proportion of unilateral tumours. The observed pattern of inheritance is consistent with that of an autosomal dominant gene.

Kundson' suggested that retinoblastoma is caused by mutational events in homologous genes on each of a pair of chromosomes, and that in the hereditary form the first of these mutations is inherited and the retinoblastoma gene is present in every cell in the body. Murphree and Benedict ${ }^{2}$ have carried this theory further by postulating that the 'wild-type' allele at the retinoblastoma locus is a suppressor for retinoblastoma; the mutant allele at this locus is recessive at the cellular level, and when there is

Correspondence to B M Sanders, Childhood Cancer Research Group, Radcliffe Infirmary, Oxford OX2 6HE. homozygosity or hemizygosity for this allele retinoblastoma will occur. This would account for the occasional association of retinoblastoma with deletion of part of chromosome 13, where the retinoblastoma gene is missing. Friend et al. ${ }^{3}$ have identified a segment of chromosome band $13 q 14$, all or part of which is frequently deleted in retinoblastoma and osteosarcoma, and assign to this segment the locus of the 'retinoblastoma gene'.

\section{Material and methods}

In this paper we include data about 431 children diagnosed with retinoblastoma in England, Scotland, and Wales between 1969 and 1980. Notifications of the tumours were received from local cancer registries. It is estimated that more than $90 \%$ of all retinoblastoma cases occurring in Britain during this period have been ascertained. Medical and epidemiological information has been obtained from the hospitals where the children were treated, and 
from their family doctors. The children have been followed up for at least five years, and for the earlier registrations for up to 17 years, from diagnosis. All surviving children have been flagged at the National Health Service Central Registers at Southport or Edinburgh in order that all subsequent cancers and deaths may be notified to us.

Our previous study of retinoblastoma in Britain included children treated from 1962 to 1968 . These children have now been followed up for a further period of 10 years. The total of 699 children with retinoblastoma diagnosed between 1962 and 1980 forms one of the largest well documented series of retinoblastoma available, with probably a better population coverage than any other large series. Some data from the 1962-8 series have been included here in analyses of incidence rates and the occurrence of second primary tumours, and for comparison of treatment regimens during the two periods.

\section{Results}

\section{INCIDENCE}

Incidence rates for retinoblastoma have often been expressed as numbers of cases per million live births and we have followed this convention in the present paper. For the calculation of these rates we have used data for patients diagnosed during 1969-80 from the present paper together with data for 1962-8 from the National Registry of Childhood Tumours maintained by the Childhood Cancer Research Group. All children notified to the national cancer registration system as having retinoblastoma before age 15 will be included in these series. These children will have been born between 1947 and 1980, though for most of these years the coverage of the age range is necessarily incomplete. For instance any child born in 1947 and diagnosed at age 1 , or born in 1980 and diagnosed at age 4, will not be included. Allowing for these 'incomplete birth cohorts' we can calculate the incidence of retinoblastoma at each year of age and also the cumulative rate by age 15 ; these figures are given separately for unilateral and bilateral cases in Table 1 . The overall incidence is about 43.9 cases per million births, that is, 1 in 23000 births. Just over $60 \%$ of the cases are unilateral, the incidence rates of unilateral and bilateral cases being respectively 1 in 37000 and 1 in 60000 births.

Incidence figures given in other papers range between 1 in 34000 and 1 in 10000 , but these outer limits are not population based. Vogel ${ }^{5}$ suggests that figures of 1 in 28000 to 1 in 15000 give reliable limits for incidence. Pendergrass and Davis ${ }^{6}$ give the annual incidence in the United States of retinoblastoma in children under 5 (by which age about $95 \%$ of cases have occurred) as 11 cases per million, that is, a
Table 1 Incidence of retinoblastoma in Britain, by age at diagnosis

\begin{tabular}{lccc}
\hline Age in years & \multicolumn{3}{c}{ Incidence per million births } \\
\cline { 2 - 4 } & Unilateral & Bilateral & Total \\
\hline 0 & $5 \cdot 0$ & $10 \cdot 0$ & $14 \cdot 9$ \\
1 & $7 \cdot 1$ & $4 \cdot 6$ & $11 \cdot 7$ \\
2 & $7 \cdot 5$ & $1 \cdot 6$ & $9 \cdot 2$ \\
3 & $4 \cdot 0$ & $0 \cdot 2$ & $4 \cdot 3$ \\
4 & $1 \cdot 9$ & $0 \cdot 1$ & $2 \cdot 0$ \\
5 & $0 \cdot 8$ & 0 & $0 \cdot 8$ \\
6 & $0 \cdot 6$ & 0 & $0 \cdot 6$ \\
7 & $0 \cdot 2$ & 0 & $0 \cdot 2$ \\
8 & $0 \cdot 1$ & 0 & $0 \cdot 1$ \\
9 & 0 & 0 & 0 \\
10 & $0 \cdot 1$ & $0 \cdot 1$ & $0 \cdot 2$ \\
$11-14$ & 0 & 0 & 0 \\
Cumulative rate by age 15 & $27 \cdot 4$ & $16 \cdot 6$ & $43 \cdot 9$ \\
\hline
\end{tabular}

cumulative rate by age 5 of 55 per million. Our figures are lower than the actual incidence in Britain because we are including only patients registered with retinoblastoma at local cancer registries. It is known that some patients, particularly those who died without treatment, have never been registered, and it is possible that incidence rates quoted here should be increased by as much as $10 \%$.

Of the 699 cases included in the analysis only four were diagnosed more than eight years after birth; the diagnosis of one bilateral case at age 10 years is remarkable. As can be seen from Table 1 the age distributions for unilateral and bilateral cases are quite different. Nearly all bilateral cases are diagnosed in the first three years of life; more than a quarter of unilateral cases are diagnosed after this. Most cases in both groups are diagnosed during the

Table 2 Incidence of retinoblastoma in children in Britain under the age of 5 years by year of birth

\begin{tabular}{llll}
\hline Year of birth & $\begin{array}{l}\text { Incidence } \\
\text { (number of cases per million live births) }\end{array}$ \\
\cline { 2 - 4 } & Unilateral & Bilateral & All cases \\
\hline 1962 & 19 & 16 & 35 \\
1963 & 17 & 10 & 27 \\
1964 & 21 & 18 & 40 \\
1965 & 22 & 15 & 36 \\
1966 & 26 & 21 & 48 \\
1967 & 32 & 17 & 50 \\
1968 & 30 & 15 & 45 \\
1969 & 28 & 15 & 43 \\
1970 & 24 & 15 & 39 \\
1971 & 26 & 11 & 38 \\
1972 & 29 & 22 & 51 \\
1973 & 33 & 20 & 53 \\
1974 & 34 & 13 & 46 \\
1975 & 18 & 16 & 34 \\
All years & 25 & 16 & 42 \\
\hline
\end{tabular}


first five years of life, and for this age group all patients born in the years 1962-75 and notified to a cancer registry are included in this analysis. The overall incidence during the first five years of life per million children born during these years was 25.5 for unilateral cases and $16 \cdot 1$ for bilateral cases. These figures are very similar to the cumulative rates for ages $0-4$ based on the complete data in Table 1 . In Table 2 the incidence rates for the age group 0-4 years are given for single years of birth from 1962 to 1975. It is clear that there is no consistent trend in either the unilateral or bilateral rate.

\section{TYPES OF TUMOUR AND FAMILY HISTORIES}

The 431 children in the present study are classified in Table 3 by sex, laterality of the tumours, and whether or not there is a known family history of retinoblastoma. There is histological confirmation of the retinoblastoma for 399 of these patients. The incidence is similar for the two sexes: 221 boys and 210 girls were affected. In $149(34.6 \%)$ children the tumours were bilateral and in $282(65.4 \%)$ children unilateral. Of the unilateral tumours 156 were sited in the right eye and 126 in the left. For one additional child registered during the study period retinoblastoma cells were found only in the suprasellar region of the brain, the eyes and the optic nerves being free of tumour; she has not been included in the analysis. This child had a strong family history of retinoblastoma; her sister and mother were both affected.

Fifty-three children had at least one other relative who had been diagnosed with retinoblastoma. This is $12 \%$ of all the children in the study and is in line with other published figures. It is notable that even for the bilateral cases only a minority, $26 \%$, are known to have a family history. Forty children had a parent previously diagnosed with retinoblastoma, and 16 of this group of 40 children had at least one sibling with retinoblastoma. Three other children had one sibling with retinoblastoma, and 10 children in the study had only a more distant relative affected with the disease. Of the remaining 378 children with no known family history of retinoblastoma those with bilateral tumours are classified as having the genetic form of the disease. One patient with bilateral tumours

Table 3 Numbers of patients with retinoblastoma

\begin{tabular}{|c|c|c|c|c|c|c|c|c|c|}
\hline \multirow[t]{2}{*}{ Site } & \multicolumn{3}{|l|}{$F H$} & \multicolumn{3}{|c|}{$\mathrm{NoFH}$} & \multicolumn{3}{|c|}{ All cases } \\
\hline & Male & Female & All & Male & Female & e All & Male & Female & e $A l l$ \\
\hline Unilateral & 7 & 8 & 15 & 135 & 132 & 267 & 142 & 140 & 282 \\
\hline Bilateral & 18 & 20 & 38 & 61 & 50 & 111 & 79 & 70 & 149 \\
\hline All cases & 25 & 28 & 53 & 196 & 182 & 378 & 221 & 210 & 431 \\
\hline
\end{tabular}

$\mathrm{FH}=$ family history .
Table 4 Ages at diagnosis

\begin{tabular}{|c|c|c|c|c|c|c|c|c|c|}
\hline \multirow{2}{*}{$\begin{array}{l}\text { Ageat } \\
\text { diagnosis } \\
\text { (months) }\end{array}$} & \multicolumn{3}{|c|}{ Unilateral } & \multicolumn{3}{|c|}{ Bilateral } & \multicolumn{3}{|c|}{ All cases } \\
\hline & $F H$ & No FH & $A l l$ & $F H$ & No FH & All & $F H$ & No FH & All \\
\hline $0-5$ & 3 & 16 & 19 & 22 & 27 & 49 & 25 & 43 & 68 \\
\hline $6-11$ & 1 & 35 & 36 & 9 & 33 & 42 & 10 & 68 & 78 \\
\hline $12-17$ & 6 & 20 & 26 & 2 & 18 & 20 & 8 & 38 & 46 \\
\hline $18-23$ & - & 42 & 42 & 2 & 13 & 15 & 2 & 55 & 57 \\
\hline $24-29$ & 1 & 46 & 47 & 2 & 10 & 12 & 3 & 56 & 59 \\
\hline $30-35$ & 2 & 29 & 31 & - & 7 & 7 & 2 & 36 & 38 \\
\hline $36-41$ & - & 21 & 21 & - & 2 & 2 & - & 23 & 23 \\
\hline $42-47$ & - & 20 & 20 & - & - & - & - & 20 & 20 \\
\hline $48-53$ & 1 & 16 & 17 & 1 & - & 1 & 2 & 16 & 18 \\
\hline $54-59$ & 1 & 5 & 6 & - & - & - & 1 & 5 & 6 \\
\hline $60-65$ & - & 3 & 3 & - & - & - & - & 3 & 3 \\
\hline $66-71$ & - & 5 & 5 & - & - & - & - & 5 & 5 \\
\hline $72+$ & - & 9 & 9 & - & 1 & 1 & - & 10 & 10 \\
\hline Total & 15 & 267 & 282 & 38 & 111 & 149 & 53 & 378 & 431 \\
\hline
\end{tabular}

$\mathrm{FH}=$ family history .

included in this study, who was first treated at the age of 10 years, has recently had a child diagnosed with retinoblastoma at the age of 2 months.

The study included a pair of monozygotic twins both of whom had retinoblastoma. One child was affected unilaterally, and the tumour regressed spontaneously without treatment. His brother, who had bilateral tumours, received radiotherapy to one eye, and the tumour in the other eye also regressed without treatment. One child with unilateral retinoblastoma had an unaffected monozygotic co-twin.

\section{AGES AT DIAGNOSIS}

The ages of the children when retinoblastoma was diagnosed ranged from 18 days to 10 years. Table 4 shows the distribution of ages for children with unilateral and bilateral tumours, subdivided according to whether or not there was a family history. These age distributions reflect the incidence rates shown in Table 1 . Bilateral cases were diagnosed at an earlier age than unilateral ones; in addition, within each group cases with a family history tended to be diagnosed earlier than those without. The unilateral tumours with no family history had their peak incidence between 24 and 29 months; more than half these children were diagnosed before the age of 30 months. The genetic tumours (bilateral or with a known family history) had their peak incidence in the first six months of life; more than half this group of children were treated before the age of 1 year.

For 130 of the 149 children with bilateral retinoblastoma the interval between diagnosis of the tumours in the two eyes was three months or less. For only six children was this interval longer than a year, and the longest interval was under three years. However, the fact that, when a tumour is discovered in one eye, the other eye is always examined care- 
fully, will probably mean that the second tumour is diagnosed earlier than would otherwise be the case and hence reduce the interval between the two diagnoses.

\section{STAGING}

The tumours were staged on the basis of medical records and histology by a modification of the system described by Reece and Ellsworth.? Their five-part staging requires more detailed clinical information than that available for most of the cases in this study. The stages used and the numbers of unilateral and

Table 5 Staging:numbers of patients ineach category

\begin{tabular}{|c|c|c|}
\hline \multirow[t]{2}{*}{ Stage } & \multicolumn{2}{|c|}{ Numbers of patients } \\
\hline & Unilateral & Bilateral \\
\hline IConfined to retina & 74 & 38 \\
\hline Il Retinaldetachment & 60 & 23 \\
\hline III Optic nerve involved but not beyond cut end & 49 & 24 \\
\hline IV Intraocular spread & 66 & 35 \\
\hline VOptic nerve involved beyond cut end & 21 & 7 \\
\hline VIExtraocular spread & 4 & 3 \\
\hline VIINorecord & 8 & 19 \\
\hline
\end{tabular}

Table 6 Treatment of patients with retinoblastoma

\begin{tabular}{|c|c|c|c|c|}
\hline \multirow[t]{2}{*}{ Initial treatment } & \multirow{2}{*}{$\begin{array}{l}\text { No. of } \\
\text { patients }\end{array}$} & \multicolumn{3}{|c|}{ Futher treatment } \\
\hline & & Enucleation & RT to socket & Conservative* \\
\hline Enucleation & $235(26)$ & - & $17(14)$ & - \\
\hline $\begin{array}{l}\text { Enucleation }+\mathrm{R} / \mathrm{T} \\
\text { socket }\end{array}$ & $30(10)$ & - & - & - \\
\hline Conservative* & $15(2)$ & $4(1)$ & & 4 \\
\hline $\begin{array}{l}\text { None } \\
\text { (spontaneous } \\
\text { regression) }\end{array}$ & 2 & - & - & - \\
\hline Total & $282(38)$ & $4(1)$ & $17(14)$ & 4 \\
\hline
\end{tabular}

Bilateral

\begin{tabular}{|c|c|c|c|}
\hline \multirow[t]{2}{*}{ Initial treatment } & \multirow{2}{*}{$\begin{array}{l}\text { No. of } \\
\text { patients }\end{array}$} & \multicolumn{2}{|c|}{ Further treatment } \\
\hline & & Enucleation & $\begin{array}{l}\text { Conservative } \\
\text { or RT to socket* }\end{array}$ \\
\hline Enucleation 2 cyes & $9(1)$ & - & - \\
\hline $\begin{array}{l}\text { Enucleation } 1 \text { eye } \\
\text { conservative* }{ }^{*} \text { treatment } \\
\text { other }\end{array}$ & $112(15)$ & $16(3)$ & $38(7)$ \\
\hline Conservative ${ }^{*}$ both eyes & $27(3)$ & $5(1)$ & 13 \\
\hline Nil & $1(1)$ & - & - \\
\hline Total & $149(20)$ & $21(4)$ & $51(7)$ \\
\hline
\end{tabular}

${ }^{*}$ Conservative treatment includes external radiotherapy to eye, cobalt plaques, light coagulation or cryotherapy.

Numbers in brackets are numbers of patients who died from retinoblastoma and ectopic intracranial retinoblastoma. bilateral cases in each group are given in Table 5. For bilateral cases the staging refers to the eye with the more advanced tumour at diagnosis.

\section{TREATMENT}

Table 6 shows the initial and subsequent treatment of 282 children with unilateral tumours and 149 children with bilateral tumours, and the numbers in each category who died. Chemotherapy has not been included in this table but is discussed later.

For the 282 children with unilateral tumours the most usual treatment was enucleation. For two children the tumours regressed without treatment; 15 other children received only radiotherapy or light coagulation initially; 13 survived, though four subsequently had the affected eye enucleated. Bilateral tumours were usually treated by enucleation of the more severely affected eye and conservative treatment (cobalt plaques, radiotherapy, light coagulation, or cryotherapy) to the other. Some vision was retained by $108(84 \%)$ of the 129 survivors from bilateral retinoblastoma; for $20(16 \%)$ of these children neither eye had been enucleated.

Table 7 compares the treatment given during the periods $1962-8$ and $1969-80$. There appears to be a trend towards more conservative treatment between the two periods: $5 \%$ of children with unilateral tumours in the later period did not have an enucleation as compared with $1 \%$ in the earlier period. For the bilateral cases at least one eye was retained for $83 \%$ of the children in the later period, as compared with $73 \%$ in the earlier.

Chemotherapy was used only in addition to other forms of treatment, never as the sole method. A total of 48 children were treated with cytotoxic drugs. Cyclophosphamide was the drug most generally used. Thirty-nine children were treated with it, in 25 cases in combination with vincristine, methotrexate, or adriamycin. Nine other children were treated with

Table 7 Comparison of treatment for retinoblastoma between periods 1962-8 and 1969-80

\begin{tabular}{|c|c|c|c|}
\hline \multirow[t]{2}{*}{ Years } & \multicolumn{3}{|l|}{ Unilateral } \\
\hline & Total cases & Eye enucleated & $\begin{array}{l}\text { Conservative or } \\
\text { no treatment }\end{array}$ \\
\hline \multirow{4}{*}{$\begin{array}{l}1962-8 \\
1969-80\end{array}$} & 157 & $155(99 \%)$ & $2(1 \%)$ \\
\hline & 282 & $269(95 \%)$ & $13(5 \%)$ \\
\hline & \multicolumn{3}{|l|}{ Bilateral } \\
\hline & Totalcases & $\begin{array}{l}\text { Botheyes One eye } \\
\text { enucleated enucleated }\end{array}$ & $\begin{array}{l}\text { Conservative } \\
\text { orno treatment }\end{array}$ \\
\hline $1962-8$ & 111 & $30(27 \%)$ & $15(14 \%)$ \\
\hline $1969-80$ & 149 & $25(17 \%) \quad 101(68 \%)$ & $23(15 \%)$ \\
\hline
\end{tabular}


dexamethasone, triethylmelamine, or vincristine. Table 8 shows the numbers of children given chemotherapy for various reasons and the numbers who died. Thirteen were given drugs as part of the initial planned treatment: 11 received cyclophosphamide, one vincristine, and one triethylmelamine. All 13 survived the retinoblastoma, but two children who had been treated with cyclophosphamide developed osteosarcomas of the leg in their teens. Both children have a strong family history of retinoblastoma.

Six children were given chemotherapy because of the advanced stage of the tumour at enucleation (optic nerve involvement or orbital spread). Four of these children died. The two who survived had been given radiotherapy to the orbit and were treated with a combination of cyclophosphamide, vincristine, methotrexate, and adriamycin for longer than a year. Among 29 other children whose tumours were found to be at similarly advanced stages when the eye was enucleated, and who were not given chemotherapy there were 12 survivors.

For 29 children the drugs were given because of a local recurrence of the retinoblastoma or distant metastases; all but one of these children died. The child who survived had been treated for six months with cyclophosphamide and vincristine as well as radiotherapy for a recurrence in the orbit and antrum which occurred 18 months after enucleation. ${ }^{8}$

SURVIVAL RATES AND CAUSES OF DEATHS

Three years after their initial treatment for retinoblastoma 374 of the 431 children were known to be still alive. Two children were lost to follow-up in this period. Of the 55 deaths three were from causes unrelated to retinoblastoma and three from ectopic intracranial retinoblastoma in the pineal gland or suprasellar region. The actuarially calculated threeyear survival rate, with deaths from unrelated causes being regarded as losses to follow-up, was $88 \%$. The survival curves for the 282 unilateral and 149 bilateral cases are shown in Fig. 1. The three-year survival rate for the bilateral group $(90.5 \%)$ was slightly better than that for the unilateral one $(86 \cdot 5 \%)$. This is similar to the finding in our previous (1962-8) series.

Table 8 Use of chemotherapy

\begin{tabular}{|c|c|c|}
\hline \multirow[t]{2}{*}{ Reason for chemotherapy } & \multicolumn{2}{|c|}{ Number of patients } \\
\hline & Treated & Died \\
\hline \multicolumn{3}{|l|}{ Initial treatment: } \\
\hline Part of initial protocol & 13 & - \\
\hline Advanced stage of tumour at enucleation & 6 & 4 \\
\hline \multicolumn{3}{|l|}{ Later treatment: } \\
\hline Orbital recurrence & 11 & 10 \\
\hline Metastatic spread & 18 & 18 \\
\hline Total & 48 & 32 \\
\hline
\end{tabular}

Table 9 Three-year survival rates for groups of patients. subdivided according to various possible prognostic factors

\begin{tabular}{|c|c|c|c|c|c|}
\hline \multirow[t]{2}{*}{ Factor } & \multirow[t]{2}{*}{ Subgroup } & \multicolumn{2}{|c|}{ Unilateral $^{*}$} & \multicolumn{2}{|c|}{ Bilateral } \\
\hline & & $\begin{array}{l}\text { No. of } \\
\text { cases }\end{array}$ & $\begin{array}{l}\text { Three- } \\
\text { year } \\
\text { survival } \\
\text { rate (\%) }\end{array}$ & $\begin{array}{l}\text { No. of } \\
\text { cases }\end{array}$ & $\begin{array}{l}\text { Three- } \\
\text { year } \\
\text { survival } \\
\text { rate }(\%)\end{array}$ \\
\hline & All cases & 281 & 86 & 149 & 90 \\
\hline \multirow[t]{2}{*}{ Sex } & Male & 141 & 91 & 79 & 92 \\
\hline & Female & 140 & 82 & 70 & 89 \\
\hline Age & $0-5$ & 19 & 95 & 49 & 88 \\
\hline \multirow[t]{6}{*}{ (months) } & $6-11$ & 36 & 89 & 42 & 98 \\
\hline & $12-17$ & 26 & 96 & 20 & 90 \\
\hline & $18-23$ & 42 & 88 & 15 & 93 \\
\hline & $24-29$ & 47 & 81 & 12 & 75 \\
\hline & $30-35$ & 31 & 77 & 7 & (86) \\
\hline & $36+$ & 80 & 86 & 4 & $(100)$ \\
\hline \multirow[t]{7}{*}{ Stage $†$} & I & 73 & 97 & 38 & 92 \\
\hline & II & 60 & 90 & 23 & 96 \\
\hline & III & 49 & 94 & 24 & 96 \\
\hline & IV & 66 & 88 & 35 & 94 \\
\hline & V & 21 & 38 & 7 & (71) \\
\hline & VI & 4 & (25) & 3 & $(0)$ \\
\hline & VII & 8 & (63) & 19 & 89 \\
\hline $\begin{array}{l}\text { Hospital } \\
\text { for initial }\end{array}$ & $\begin{array}{l}\text { Major UK referral } \\
\text { centre }\end{array}$ & 77 & 91 & 94 & 94 \\
\hline treatment & Specialist eye & 74 & 89 & 11 & 91 \\
\hline & $\begin{array}{l}\text { With ophthalmic } \\
\text { surgeon }\end{array}$ & 126 & 82 & 43 & 86 \\
\hline & Other & 4 & $(100)$ & 1 & $(0)$ \\
\hline
\end{tabular}

*One patient with no follow-up information is excluded.

†For definition of stage see 'Methods' section.

() Fewer than 10 cases.

The long-term survival rate, however, was worse for the bilateral cases. The average period of further follow-up for those who survived three years was eight years. No further deaths have been observed among the unilateral cases, but there have been nine in the bilateral group, one from disseminated retinoblastoma five years after the original treatment, five more from ectopic intracranial retinoblastoma, and three from second primary neoplasms.

The three-year survival rate for the 1962-8 series of retinoblastomas was $87 \%$. The surviving children in that study have now been followed up for between 16 and 22 years. There have been two further deaths from retinoblastoma, and eight children, all with bilateral tumours, have died from second primary neoplasms.

Thus in retinoblastoma most of the deaths occur within three years and are directly attributable to the original disease; very few deaths occur after this. Virtually all of these are in the bilateral group and the great majority are due either to ectopic intracranial retinoblastoma or to second primary neoplasms. The long-term survival rate for the bilateral group becomes worse than that for the unilateral group. 


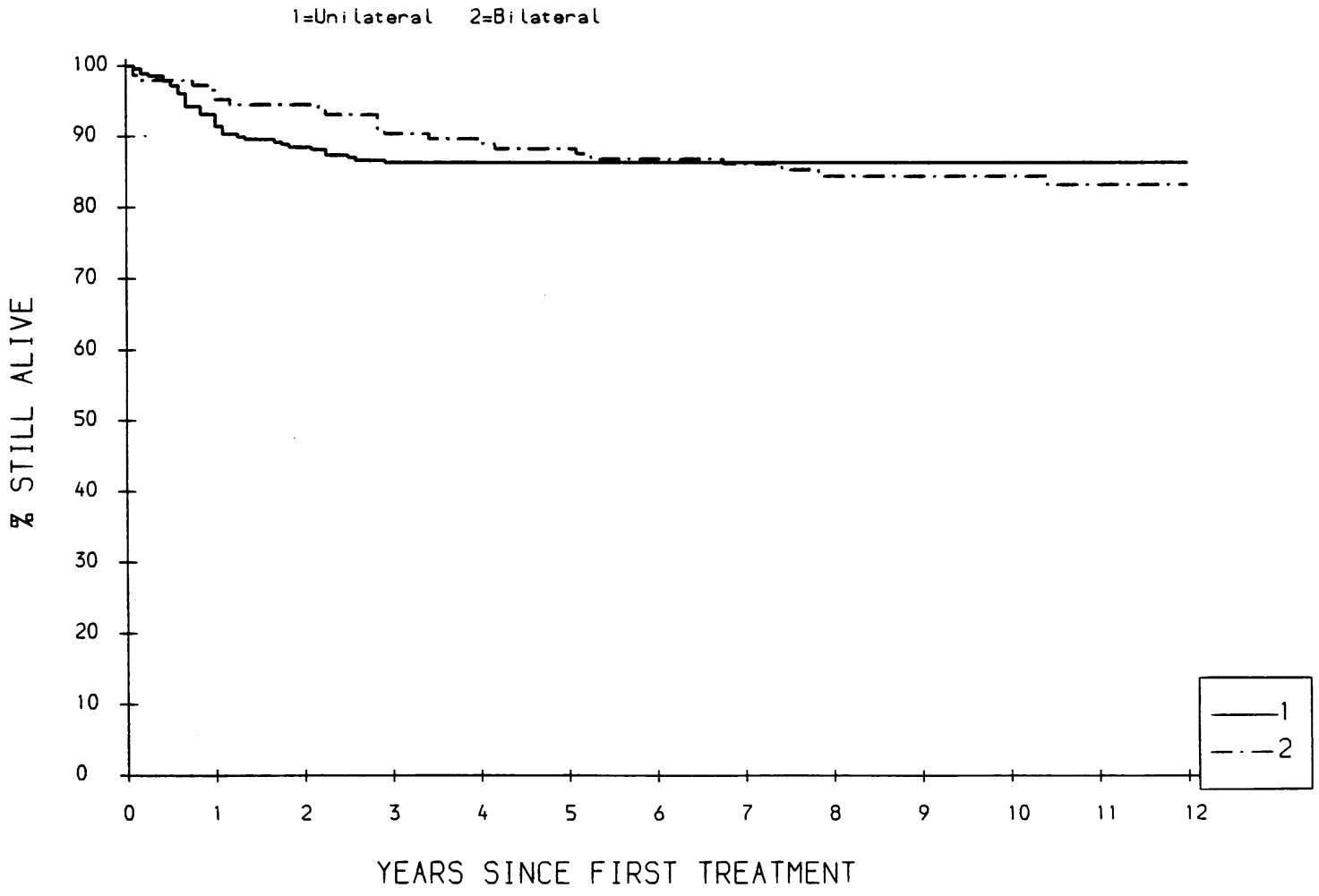

Fig. 1 Survival for retinoblastoma patients treated 1969-80.

\section{PROGNOSTIC FACTORS}

The effects of various factors on the three-year survival rate are summarised in Table 9.

Tumour stage and age at diagnosis. The staging system used in this paper is described above. As would be expected, there were large and highly significant differences in survival for the different groups (Table 9). It can also be seen from Table 9 that older children, that is, those aged 2 years or more at the time of diagnosis, tended to have a worse prognosis. This is largely accounted for by the fact that these children tended to be diagnosed at a more advanced stage.

Sex. The overall survival rate for males was better than for females in both the unilateral and bilateral groups. The difference is significant $(p<0.05)$ for the unilateral group and for the two groups combined. This finding is largely attributable to differences in the age and stage distribution for males and females.

Treatment hospitals. Just over a quarter of the unilateral cases and nearly two-thirds of the bilateral cases were given their initial treatment at two London hospitals working jointly as the major United Kingdom referral centre for retinoblastoma. The three-year survival rates for patients treated initially at this centre were $91 \%$ and $94 \%$ respectively for unilateral and bilateral cases. These were slightly better than those for other specialist eye hospitals ( $89 \%$ and $91 \%$ ), which in turn were better than those for the remaining hospitals. After allowance is made for the effects of stage and age at diagnosis there is a significant trend $(p=0.014)$ in survival rate for the unilateral cases; patients treated at the major centre have the best outcome followed by those treated at specialist eye hospitals. A similar analysis for the bilateral cases shows that the difference is not statistically significant. It is possible that this is because the major centre is actually treating the more difficult cases but the staging system used here is not sufficiently sensitive to reveal the effects of such case selection.

\section{SECOND PRIMARY NEOPLASMS}

In the present series five children developed second primary neoplasms: four of these were osteosarcomas, three of the leg and one of the orbit, and the fifth child developed acute lymphatic leukaemia. Three of these children have died.

In all, among the 699 children treated for retinoblastoma between 1962 and 1980, and included in our 
two reports, 609 survived for at least three years. Thirteen of these children have since developed second primary neoplasms of a distinct histology from retinoblastoma, and 11 of the children have died from the second neoplasm. Of the total of 13 cases, three osteosarcomas, one brain tumour, and two fibrosarcomas developed within the radiation field. One child treated with high doses of radiation developed leukaemia. These seven second primary neoplasms could have been attributed at least partly to radiotherapy given to the retinoblastoma. However, the other six children all developed osteosarcomas of the leg, outside any field of radiation; indeed one child received no radiotherapy for the earlier retinoblastoma. Nine of 13 children who developed second primary neoplasms had been given cyclophosphamide as part of their treatment. This is a higher proportion than would have been expected from the proportion of patients known to be treatd with cyclophosphamide. However, patients treated with this drug are not representative of the total group of patients, and it is hard to say whether or not it was a factor in the causation of some of the second tumours. A full discussion is given in Draper et al. ${ }^{9}$

\section{Discussion}

The incidence of retinoblastoma found in the present paper is similar to that from earlier reports. We have found no evidence of a change in incidence in recent years. The age distributions are presented here in more detail than in earlier publications and show the well known difference in age distributions for unilateral and bilateral cases; the latter have a much earlier onset. More than half the genetic tumours were treated under the age of 1 year. On the assumption that two mutational events are necessary for the development of retinoblastoma, ${ }^{10}$ this earlier age of onset can be explained by the fact that in genetic cases the first mutation for the retinoblastoma gene is inherited and present in every cell in the body.

Ectopic intracranial retinoblastoma was recognised as a clinical entity only in $1977 .{ }^{11}$ During the period covered by the present study eight cases of retinoblastoma followed by ectopic intracranial retinoblastoma were identified, a proportion of $1.9 \%$ of all cases, or $5.4 \%$ of the bilateral cases. During the earlier period, 1962 to 1968 , no cases of trilateral retinoblastoma were recorded, though it may well be the case that some of the children who were said to have died of intracranial or brain metastases actually had pineal retinoblastoma. Among 432 children with bilateral retinoblastoma described by Kingston et al. ${ }^{12} 10(2 \cdot 3 \%)$ developed ectopic intracranial retinoblastoma.
As compared with our earlier paper there is some indication of a trend towards more conservative treatment. It appears that this has continued in more recent years, at least in United Kingdom centres specialising in the treatment of this disease.

The use of chemotherapy as part of the treatment for retinoblastoma has declined since the 1960s. For the years of treatment 1962 to $1968,12 \%$ of patients were given chemotherapy as part of the initial treatment. This proportion decreased to $4 \%$ for the period 1969 to 1980 . The two London hospitals which between them treat over $40 \%$ of all retinoblastoma patients in Britain have discontinued the use of chemotherapy except for orbital recurrences, metastatic disease, and children with extensive and deep choroidal invasion.

There has been a continuing trend towards centralisation of treatment for bilateral cases. In the period $1962-850 \%$ of the children with bilateral tumours received their initial treatment at the major UK referral centre; by 1969-80 this proportion had increased to $63 \%$. The proportion of children with unilateral tumours treated at this major centre $(27 \%)$ was almost identical in the two periods.

There has been very little change in the already high three-year survival rate for retinoblastoma in Britain between the periods $1962-8$ and $1969-80$, the high survival rate being due to the policy of referral to specialist centres. The great majority of deaths from retinoblastoma occur within three years of diagnosis. Beyond that period, for survivors from genetic retinoblastoma the risk of developing second primary neoplasms assumes an increasing importance in childhood and adult life. The cumulative incidence rate of all second primary neoplasms among survivors from genetic retinoblastoma has been reported as $8.4 \%$ after 18 years; ${ }^{9}$ for osteosarcoma alone the corresponding figure is $6 \%$. It is now thought ${ }^{13}$ that some osteosarcomas may be associated with homozygosity or hemizygosity of the mutant allele at the retinoblastoma locus-13q14 and that the same mutation may predispose towards osteosarcoma.

\footnotetext{
We thank the many consultants and general practitioners who provided the information on which this paper is based. We are grateful to the Office of Population Censuses and Surveys, the Information Services Division of the Common Services Agency of the Scottish Health Service, the Registrar General for Scotland, and regional cancer registries for providing copies of notifications of childhood cancer cases. We thank the National Health Service Central Registers at Southport and Edinburgh for notification of deaths and the 'flagging' of survivors. We are grateful to Dr E L Lennox for help with the medical records, to Mr C W P Fearnley and Dr M Potok for computing assistance, and to Mrs E M Roberts for her part in collecting the medical records and typing the paper.

The Childhood Cancer Research Group is supported by the Department of Health and Social Security and the Scottish Home and Health Department.
} 


\section{References}

1 Knudson AG Jr. Retinoblastoma: a prototypic hereditary neoplasm. Semin Oncol 1978; 5: 57-60.

2 Murphree AL, Benedict WF. Retinoblastoma: clues to human oncogenesis. Science 1984; 223: 1028-33.

3 Friend SH, Bernards R, Rogelj S, et al. A human DNA segment with properties of the gene that predisposes to retinoblastoma and osteosarcoma. Nature 1986; 323: 643-6.

4 Lennox EL, Draper GJ, Sanders BM. Retinoblastoma: A study of natural history and prognosis of 268 cases. Br Med J 1975; iii: $731-4$.

5 Vogel F. Genetics of retinoblastoma. Hum Genet 1979; 52: 1-54.

6 Pendergrass TW, Davis S. Incidence of retinoblastoma in the United States. Arch Ophthalmol 1980; 98: 1204-10.

7 Reece AB. Ellsworth RM. Evaluation and current concepts of retinoblastoma therapy. Ophthalmology $1963 ; 67: 164-72$.

8 Hungerford JL, Kingston JE, Plowman PN. Orbital recurrence in retinoblastoma. Ophthalmic Paediatr Genet 1987; 8: 63-8.

9 Draper GJ, Sanders BM, Kingston JE. Retinoblastoma and second primary tumours. Br J Cancer 1986; 53: 661-71.

10 Knudson AG. Mutation and cancer: statistical study of retinoblastoma. Proc Natl Acad Sci USA 1971; 68: 820-3.

11 Jacobiec FA. Tso MOM. Zimmerman LE, Danis P. Retinoblastoma and intracranial malignancy. Cancer 1977; 39: 2048-58.

12 Kingston JE, Plowman PN, Hungerford JL. Ectopic int racranial retinoblastoma in childhood. BrJ Ophthalmol 1985; 69: 742-8.

13 Dryja TP, Rapaport JM, Epstein J, et al. Chromosome 13 homozygosity in osteosarcoma without retinoblastoma. $A m \mathrm{~J}$ Hum Genet 1986; 38: 59-66.

Accepted for publication 4 June 1987. 